\title{
Role of Extracellular Sialic Acid in Regulation of Neuronal and Network Excitability in the Rat Hippocampus
}

\author{
Dmytro Isaev, ${ }^{1,2,3,4}$ Elena Isaeva, ${ }^{1,2,3,4}$ Tatiana Shatskih, ${ }^{1,2,3}$ Qian Zhao, ${ }^{1,2,3}$ Nicole C. Smits, ${ }^{2}$ Nicholas W. Shworak, ${ }^{2}$ \\ Rustem Khazipov, ${ }^{1,2,3,5}$ and Gregory L. Holmes ${ }^{1,2,3}$ \\ ${ }^{1}$ Neuroscience Center at Dartmouth, ${ }^{2}$ Department of Medicine, and ${ }^{3}$ Section of Neurology, Dartmouth Medical School, Lebanon, New Hampshire 03756, \\ ${ }^{4}$ Bogomoletz Institute of Physiology, Kiev, Ukraine 01024, and ${ }^{5}$ Institute de Neurobiologie de la Méditeranée, Inserm-U29, 13273 Marseille, France
}

\begin{abstract}
The extracellular membrane surface contains a substantial amount of negatively charged sialic acid residues. Some of the sialic acids are located close to the pore of voltage-gated channel, substantially influencing their gating properties. However, the role of sialylation of the extracellular membrane in modulation of neuronal and network activity remains primarily unknown. The level of sialylation is controlled by neuraminidase (NEU), the key enzyme that cleaves sialic acids. Here we show that NEU treatment causes a large depolarizing shift of voltage-gated sodium channel activation/inactivation and action potential (AP) threshold without any change in the resting membrane potential of hippocampal CA3 pyramidal neurons. Cleavage of sialic acids by NEU also reduced sensitivity of sodium channel gating and AP threshold to extracellular calcium. At the network level, exogenous NEU exerted powerful anticonvulsive action both in vitro and in acute and chronic in vivo models of epilepsy. In contrast, a NEU blocker ( $\mathrm{N}$-acetyl-2,3-dehydro-2-deoxyneuraminic acid) dramatically reduced seizure threshold and aggravated hippocampal seizures. Thus, sialylation appears to be a powerful mechanism to control neuronal and network excitability. We propose that decreasing the amount of extracellular sialic acid residues can be a useful approach to reduce neuronal excitability and serve as a novel therapeutic approach in the treatment of seizures.
\end{abstract}

Key words: sialic acid; neuraminidase; seizure; surface charge; hippocampus; sodium channels

\section{Introduction}

The surface charges associated with the channel protein or adjacent membrane lipid phases contribute significantly to the field near the channel voltage sensor (Frankenhaeuser and Hodgkin, 1957; Campbell and Hille, 1976; Green and Andersen, 1991). There are several sources that produce surface charge near voltage-gated channels: charged amino acids and other hydrophilic residues of channel proteins, phosphates, sialic acid residues, and charged lipids (Green and Andersen, 1991). Neutralization of the negative surface charges by divalent cations shifts the activation of voltage-gated channels to more positive values (Frankenhaeuser and Hodgkin, 1957; Campbell and Hille, 1976; Kostyuk and Krishtal, 1977; Hanck and Sheets, 1992). Voltagegated sodium channels are heavily glycosylated, with a large fraction of carbohydrate in the form of negatively charged sialic acid (Miller et al., 1983; Messner et al., 1985; Roberts and Barchi, 1987). For example, the sodium channel from an electric eel was found to have $30 \%$ of its weight in carbohydrates (500 sugars of mostly sialic acid and $N$-acetylglucosamine). Muscle and brain sodium channels also have a significant content of sialic acid

Received July 17, 2006; revised Aug. 25, 2007; accepted Sept. 3, 2007.

This work was supported in part by National Institutes of Health Grants NS41595 and NS44296, the Epilepsy Foundation, and the NATO Science Program. We thank Flobert Tanga and Pierre-Pascual Lenck-Santini for support and useful discussions.

Correspondence should be addressed to Dr. Dmytro Isaev, Department of Physiology of Nervous System, Bogomoletz Institute of Physiology, Bogomoletz Street 4, Kiev, Ukraine 01024. E-mail: dmytro.isaev@gmail.com.

DOI:10.1523/JNEUROSCI.2033-07.2007

Copyright $\odot 2007$ Society for Neuroscience $\quad 0270-6474 / 07 / 2711587-08 \$ 15.00 / 0$ residues on the glycosylation sites of the extracellular region (Messner et al., 1985; Roberts and Barchi, 1987). Treatment of eel electroplax or rat skeletal muscle sodium channels with neuraminidase (NEU) to reduce the level of sialylation of channel proteins causes a large depolarizing shift of steady-state activation and inactivation (Recio-Pinto et al., 1990; Bennett et al., 1997). The level of sialylation of sodium channels changes during postnatal development, and such alteration in the sialylation level correlates with changes in voltage-dependent channel gating (Castillo et al., 1997; Tyrrell et al., 2001; Stocker and Bennett, 2006). The isoform-specific effects of sialic acid on sodium channel gating have also been well documented (Zhang et al., 1999; Bennett, 2002; Johnson et al., 2004; Johnson and Bennett, 2006). However, the functional role of glycosylation of a central neuronal voltage-gated sodium channel remains unclear. The purpose of our present study was to examine the role of sialylation of the extracellular membrane in neuronal excitability in vitro and in vivo. Despite the fact that other neuronal voltage-gated channels are glycosylated (Misonou and Trimmer, 2004) and their desialylation can affect neuronal activity, in this study we focused our attention on two questions: the role of sialylation of the extracellular membrane on the properties of neuronal voltage-gated sodium channels, which play a pivotal role in initiation of the action potential (AP), and the effect of modulating the amount of sialic acid on neuronal excitability. Using electrophysiological recordings from the rat hippocampus and the specific enzyme NEU, which cleaves negatively charged sialic acids from the membrane surface, we show that the reduction in the amount of sialic acid 
residues from the cellular membrane significantly influenced the kinetic parameters of the sodium channels and AP threshold recorded from hippocampal CA3 pyramidal cells and that these NEU-mediated changes were translated at the network level to changes in seizure threshold.

\section{Materials and Methods}

Animals. Sprague Dawley rat pups $(n=91)$ of postnatal day 2 (P2) to P21 for in vitro and in vivo studies and adult male Sprague Dawley rats (P60; $n=17)$ for kindling studies were used and treated in accordance with the guidelines set by the National Institutes of Health and Dartmouth Medical School for the humane treatment of animals.

Slice preparation. Hippocampal slices were prepared as described previously (Khazipov et al., 2004; Isaev et al., 2005). Briefly, rats were deeply anesthetized with isoflurane and decapitated. Transverse hippocampal slices $(500 \mu \mathrm{m})$ were cut using a Leica (Nussloch, Germany) VT $1000 \mathrm{~S}$ vibroslicer in an ice-cold sucrose-based solution (in mM): 250 sucrose, 2 $\mathrm{KCl}, 0.5 \mathrm{CaCl}_{2}, 7 \mathrm{MgCl}_{2}, 26 \mathrm{NaHCO}_{3}, 1.2 \mathrm{NaH}_{2} \mathrm{PO}_{4}$, and 11 glucose, $\mathrm{pH}$ 7.4. Slices were then transferred to an incubation chamber with oxygenated $\left(95 \% \mathrm{O}_{2}, 5 \% \mathrm{CO}_{2}\right)$ artificial CSF (ACSF) of the following composition (in mM): $126 \mathrm{NaCl}, 3.5 \mathrm{KCl}, 2.0 \mathrm{CaCl}_{2}, 1.3 \mathrm{MgCl}_{2}, 25 \mathrm{NaHCO}_{3}, 1.2$ $\mathrm{NaH}_{2} \mathrm{PO}_{4}$, and 11 glucose, $\mathrm{pH}$ 7.3.

Treatment with NEU. For electrophysiological studies, in vitro hippocampal slices were incubated in ACSF with or without NEU from Vibrio cholerae (Sigma, St. Louis, MO) or NEU from Arthrobacter ureafaciens (Roche, Basel, Switzerland) $(0.02 \mathrm{U} / \mathrm{ml})$ for $2 \mathrm{~h}$ at $32-34^{\circ} \mathrm{C}$ before recordings. This technique allowed us to decrease the amount of sialic acid residues on the extracellular membrane (Wieraszko, 1985). The concentration of NEU in our study was much lower than in a previous study by Wieraszko (1985). However, our conditions were sufficient to achieve a profound degree of sialic acid removal, as validated by our histochemical studies. There were no differences between the electrophysiological and histochemical data obtained from the slices incubated with NEU from the two different sources. For the studies with NEU blocker, we added $50 \mu \mathrm{M} N$-acetyl-2,3-dehydro-2-deoxyneuraminic acid (Sigma) in ACSF solution 5 min before adding NEU.

Histochemical studies. The efficiency of NEU treatment was evaluated using horseradish peroxidase-conjugated pure Sambucus nigra agglutinin lectin (SNA-I) from elderberry (EY Laboratories, San Mateo, CA), which binds to a specific terminal motif that contains a sialic acid, $N$-acetyl-neuraminic $\operatorname{acid}_{\alpha(2,6)}$ galactose/ $N$-acetyl-galactosamine $[\operatorname{Neu} 5 \mathrm{Ac} \alpha(2,6) \mathrm{Gal} / \mathrm{GalNAc}]$. Lectin histochemistry was performed using a similar procedure to that described by Sato and Endo (1999). In brief, hippocampal slices were treated with and without NEU and NEU blocker as described above, washed three to four times in ACSF, and mounted on gelatin-coated slides. Slices were air dried, hydrated in PBS for $20 \mathrm{~min}$, and fixed by incubation with $3.7 \%$ formaldehyde in $10 \mathrm{~mm}$ Tris- $\mathrm{HCl}, \mathrm{pH} 7.4,0.14 \mathrm{M} \mathrm{NaCl}, 1 \mathrm{~mm} \mathrm{CaCl}, 1 \mathrm{~mm} \mathrm{MgCl}_{2}$, and $1 \mathrm{~mm}$ $\mathrm{MnCl}_{2}$ (TBS) three times for $10 \mathrm{~min}$. Then they were immersed with $0.3 \% \mathrm{H}_{2} \mathrm{O}_{2}$ in $\mathrm{PBS}$ for $30 \mathrm{~min}$ at room temperature. After being washed with TBS three times for $30 \mathrm{~min}$, the slices were incubated with $3 \%$ bovine serum albumin (BSA) in TBS for $1 \mathrm{~h}$ at room temperature. Slices were washed again three times with TBS for $30 \mathrm{~min}$ at room temperature, followed by incubation with horseradish peroxidase-conjugated lectin SNA-I $(25 \mu \mathrm{g} / \mathrm{ml}$ in $3 \%$ BSA-TBS $)$ for $90 \mathrm{~min}$ at room temperature. Slices were washed with TBS three times for $30 \mathrm{~min}$, followed by a wash with PBS. They were then incubated with $0.05 \%$ diaminobenzidine tetrahydrochloride and $0.3 \% \mathrm{H}_{2} \mathrm{O}_{2}$ in TBS for $20 \mathrm{~min}$ at room temperature. Slices were washed with distilled water, dehydrated in ascending concentrations of ethanol, cleared in xylene, and mounted with permount. To control for nonspecific background staining, the lectin was omitted in some slices.

Patch-clamp studies. All patch-clamp recordings were made from hippocampal CA3 pyramidal cells. Brain slices were transferred to a submerged thermostatic chamber mounted to the microscope (BX51WI; Olympus, Oberkochen, Germany) and continuously superfused with oxygenated ACSF at a rate of $2-4 \mathrm{ml} / \mathrm{min}$ at $30-32^{\circ} \mathrm{C}$. The recordings were performed using an Axopatch 200B amplifier (Molecular Devices, Union
City, CA). Patch electrodes were made from borosilicate glass capillaries (GC150F-15; Clark Electromedical Instruments, Pangbourne, UK) and filled with a solution of the following composition (in mM): $100 \mathrm{CsF}, 30$ TEACl, $8 \mathrm{NaCl}$, 10 EGTA, 10 Tris, and $2 \mathrm{MgATP}$. Pipette resistances ranged from 5 to $8 \mathrm{M} \Omega$, and seal resistances were $1-10 \mathrm{G} \Omega$. Pipette and membrane capacitance were compensated to achieve minimal capacitive transients. For whole-cell recordings, series resistance was compensated by $80-85 \%$ (lag, $20 \mu \mathrm{s}$ ) to minimize the voltage error. Liquid junction potentials were calculated and corrected for all experiments. Transient and leakage currents were digitally subtracted using a $P / n$ protocol.

Experiments investigating the effect of NEU treatment on the kinetic properties of sodium channels were performed under voltage-clamp mode in whole-cell configuration from $\mathrm{P} 2-\mathrm{P} 5$ rats and in outside-out nucleated patch configuration from P10-P17 rats. Nucleated patches (Sather et al., 1992) were extracted from the soma of CA3 pyramidal neurons under visual control using infrared video microscopy. Recordings were made in the presence of $30 \mu \mathrm{M} \mathrm{NiCl}_{2}$ in the extracellular solution (to block calcium currents). Application of $1 \mu \mathrm{M}$ tetrodotoxin (TTX) completely abolished $I_{\mathrm{Na}}$, indicating that this current was mediated by TTX-sensitive voltage-gated sodium channels. Steady-state activation was studied by measuring the peak sodium conductance $\left(G_{\mathrm{Na}}\right)$ during a $100 \mathrm{~ms}$ test pulse to various test potentials from a holding potential of $-80 \mathrm{mV}$. $G_{\mathrm{Na}}$ was calculated from $G_{\mathrm{Na}}=I_{\mathrm{Na}} /\left(V-V_{\mathrm{rev}}\right)$, where $I_{\mathrm{Na}}$ is the peak of sodium current during the test depolarization $(V)$ and $V_{\text {rev }}$ is the sodium reversal potential obtained from the currentvoltage relationships of sodium currents and corresponded to the value calculated from the Nernst equation for the given extracellular and intracellular sodium concentrations. Data were normalized to maximum peak conductance $\left(G_{\max }\right)$ and fit by a Boltzmann distribution. For studying the steady-state fast inactivation, cells were held at prepulse potentials ranging from -120 to $+20 \mathrm{mV}$ for $200 \mathrm{~ms}$ and subjected to a $10 \mathrm{mV}$ test pulse for $25 \mathrm{~ms}$. Normalized peak currents were plotted versus prepulse potentials, and curves were fitted by the Boltzmann function.

Resting membrane potential (RMP) and AP threshold were recorded using current-clamp mode in whole-cell configuration from P8-P21 rats. The average membrane potential $\left(E_{m}\right)$ was determined as a mean value of the membrane potential obtained during a recording of 2-3 min in current-clamp mode with null current. Recordings were only obtained from cells with a membrane potential $\left(E_{m}\right)$ of not less than $-60 \mathrm{mV}$. APs were evoked by injecting depolarizing rectangular current pulses from a membrane potential near $-80 \mathrm{mV}$ held by steady current injection. Current strength was increased at $10 \mathrm{pA}$ increments until spike failure occurred within the $600 \mathrm{~ms}$ duration pulse. Spike threshold was determined by finding the potential at which the second derivative of the voltage waveform exceeded three times its SD in the period preceding spike onset (Erisir et al., 1999).

In vitro extracellular recordings. The effect of NEU treatment on the probability of evoking seizures was studied using extracellular recordings from the CA3 pyramidal cell layer in slices from P8 -P21 rats using metal electrodes of $50 \mu \mathrm{m}$ diameter Recordings were made simultaneously from pairs of slices (control and NEU treated) using a two-channel microelectrode amplifier. The procedure of NEU treatment of the slices was the same as described above. In the experiments with high-potassium and low magnesium, $\mathrm{MgCl}_{2}$ was not added to ACSF, and $10 \mathrm{~mm} \mathrm{KCl}$ was substituted for the equivalent concentration of $\mathrm{NaCl}$.

In vivo high-potassium model of epilepsy. The experimental setup for recording in vivo was similar to that described in detail previously (Leinekugel et al., 2002; Isaev et al., 2005). Briefly, the application cannula $(0.2 \mathrm{~mm})$ with an internal wire electrode $(0.02 \mathrm{~mm})$ was implanted into the hippocampus of P8-P21 rats under deep anesthesia with isoflurane in an $\mathrm{O}_{2}$ carrier (induction, $4 \%$; maintenance, 2\%) using an agentspecific vaporizer. For general analgesia, buprenex $(0.01-0.02 \mathrm{mg} / \mathrm{kg}$ buprenorphine hydrochloride) was administered subcutaneously. The application cannula with recording electrode was positioned into the CA3 pyramidal cell layer under stereotaxic and electrophysiological guidance $(2.0-2.5 \mathrm{~mm}$ caudal to bregma; $2.0-2.5 \mathrm{~mm}$ from midline; depth, 2.7-3.1 mm). NEU (4 U/ml) or NEU blocker (5 mM N-acetyl-2,3dehydro-2-deoxyneuraminic acid; Sigma) was dissolved in the ACSF; 30 $\mu \mathrm{l}$ of ACSF containing NEU or NEU blocker was then applied in three 
equal injections of $10 \mu \mathrm{l}$ volume at $5 \mathrm{~min}$ intervals into the CA3 rat hippocampus (for controls, we injected $30 \mu \mathrm{l}$ of normal ACSF). The rat remained under anesthesia for $2 \mathrm{~h}$. Before additional studies were performed, the rat pup was allowed to recover from the anesthesia for 10-15 $\mathrm{min}$. The head was restrained by skull bars, and the body was surrounded by a cotton nest, mimicking the presence of a litter. Electrophysiological data were then recorded uninterrupted for 60-120 min. Application of $10 \mathrm{~mm}\left[\mathrm{~K}^{+}\right]_{\mathrm{o}} /$ low $\left[\mathrm{Mg}^{2+}\right]_{\mathrm{o}}$ ACSF was made by repetitive injections of 5 $\mu \mathrm{l}$ volumes (duration, $10-15 \mathrm{~s}$; interval, $5 \mathrm{~min}$; iterations, up to 10 times).

Kindling model of epilepsy. Young adult rats $(\mathrm{P} 60 ; n=17)$ were anesthetized using a dose of $45 \mathrm{mg} / \mathrm{kg}$ Nembutal sodium solution. After adequate anesthesia, rats were placed in a stereotaxic frame. The top of the head was shaved with an electric razor; the skin was cleaned with iodine. The skull was exposed, and securing screws were placed over the right olfactory bulb and the right cerebellar hemisphere. A stimulating electrode was placed in the CA3 region, and a recording electrode/cannula guide was implanted in the CA1 field of the right hippocampus. The coordinates (all with respect to bregma) were as follows: CA3: $3.8 \mathrm{~mm}$ posterior, $5 \mathrm{~mm}$ lateral, and $3.4 \mathrm{~mm}$ below dura with an $18^{\circ}$ angle; CA1: $3.8 \mathrm{~mm}$ posterior, $2.5 \mathrm{~mm}$ lateral, and $2 \mathrm{~mm}$ below dura (Paxinos and Watson, 1998). The electrodes were secured to the head using cranioplast cement. Rats were allowed to recover for 1 week after surgery before additional procedures were performed.

The afterdischarge thresholds (ADT) were measured in awake, freely moving rats. Increasing intensities of bipolar current pulses were delivered from a Grass Instruments (Quincy, MA) stimulation unit (1 s, 50 $\mathrm{Hz}, 1 \mathrm{~ms}$ pulse width) beginning at $15 \mu \mathrm{A}$ and increasing in $10 \mu \mathrm{A}$ increments with an interval of 30 min until an afterdischarge (AD) was elicited (operationally defined as a $>1 \mathrm{~s}$ burst of rhythmic spikes). At that point, the animal was given a $60 \mathrm{~min}$ rest period, and the stimulus that caused the $\mathrm{AD}$ was repeated. If this stimulus did not result in an $\mathrm{AD}$, then the current was increased in $10 \mu \mathrm{A}$ increments until two consecutive ADs were elicited. Once two ADs were obtained, the current intensity was reduced by $5 \mu \mathrm{A}$. If an $\mathrm{AD}$ was still obtained, then that current intensity was defined as the ADT; if an $\mathrm{AD}$ did not occur, then the previous higher current intensity was designated as the ADT. A suprathreshold current 50 $\mu \mathrm{A}$ higher than the ADT was then set as the kindling stimulus.

After determining the ADT for each rat, we administered the suprathreshold current stimulus train ( $2 \mathrm{~s}, 20 \mathrm{~Hz}, 5 \mathrm{~ms}$ pulse width) every $1 \mathrm{~h}$, three to eight times per day until rats were fully kindled. EEGs were recorded before, during, and after the stimulation for the duration of the $\mathrm{AD}$. Behavioral seizure stages were scored as follows: class 1, facial clonus; class 2, head nodding and wet dog shaking; class 3, contralateral (to stimulating electrode) forelimb clonus; class 4 , rearing; class 5 , rearing and falling (Racine, 1972). Full kindling was operationally defined as three stage 5 seizures over consecutive $1 \mathrm{~h}$ intervals.

After completion of the kindling, rats that had been fully kindled were tested for seizure susceptibility, after either injection of NEU alone or $\mathrm{NEU}$ with its blocker using the same electrical stimulation parameters as during the kindling procedure. We used NEU from A. ureafaciens (Roche), which was supplied as a $1 \mathrm{U} / 100 \mu \mathrm{l}$ solution $(25 \mathrm{U} / \mathrm{mg}$ total protein $=100 \mathrm{U} / \mathrm{mg}$ enzyme protein), and NEU from $V$. cholerae (Sigma) supplied as a $1.77 \mathrm{mg}$ protein $/ \mathrm{ml}$ solution with the specific activity of $1-5 \mathrm{U} / \mathrm{mg}$ protein (Lowry et al., 1951) and stored at $4^{\circ} \mathrm{C}$ until used. NEU was blocked with $N$-acetyl-2.3-dehydro-2-deoxyneuraminic acid (Sigma), which we prepared as a $5 \mathrm{~mm}$ solution in ACSF (final $\mathrm{pH}$ of 7.3). The blocker was stored at $-25^{\circ} \mathrm{C}$ until used.

In the first experiment, we tested rats $(n=10)$ for seizure susceptibility after the injection of NEU. Immediately after full kindling was achieved, rats received an injection of NEU through the cannula implanted in the CA1 region of the right hippocampus $(30,40$, or $60 \mu \mathrm{l})$. After $1 \mathrm{~h}$, rats were administered the kindling stimulus. After $12 \mathrm{~h}$, rats received three more stimulations with an interval of $1 \mathrm{~h}$ between stimulations.

In the second experiment, we tested rats $(n=7)$ for seizure susceptibility after the injection of NEU blocker and NEU. One hour after full kindling was achieved, rats received injections of NEU blocker, and after $45 \mathrm{~min}$, NEU was injected through the cannula implanted in the CA1 region of the right hippocampus in the following combinations: $30 \mu \mathrm{l}$ of blocker and $30 \mu \mathrm{l}$ of NEU; $30 \mu \mathrm{l}$ of blocker and $40 \mu \mathrm{l}$ of NEU; and $60 \mu \mathrm{l}$ of blocker and $60 \mu \mathrm{l}$ of NEU. Stimulation was administered immediately after blocker injection, and a second stimulation was given just before NEU injection. After $1 \mathrm{~h}$, rats were administered one more stimulation. After $12 \mathrm{~h}$, rats received three more stimulations with $1 \mathrm{~h}$ between stimulations.

Behavioral seizure stages and $\mathrm{AD}$ durations were measured after each kindling stimulation and compared with predrug kindling stages and $\mathrm{AD}$ durations. The effects of NEU on rat activity level, posture, and response to handling was recorded.

Histology. Animals were killed at the completion of the testing. After deep anesthesia with sodium pentobarbital ( $80 \mathrm{mg} / \mathrm{kg}$ intraperitoneally), rats were perfused transcardially with $200 \mathrm{ml}$ of normal saline followed by $200 \mathrm{ml}$ of $4 \%$ paraformaldehyde (PFA). The brains were postfixed in PFA for $24 \mathrm{~h}$ and placed in a $30 \%$ sucrose solution until the brains sank to the bottom of the chamber. Coronal sections through the hippocampus were cut at $40 \mu \mathrm{m}$ on a freezing microtome, and sections were stored in PBS, pH 7.3. Every fourth section was stained with thionin. Electrode/ cannula placement and cell loss were evaluated in each animal.

Data acquisition and analysis. The recordings were digitized $(10 \mathrm{kHz})$ on-line with an analog-to-digital converter Digidata 1322A (Molecular Devices). Clampex and Clampfit (Molecular Devices), Mini Analysis (version 5.5; Synaptosoft, Decatur, GA), and Origin 7.0 (Microcal Software, Northampton, MA) software were used for the acquisition and data analysis.

Group measures were expressed as means \pm SEM; error bars also indicate SEM. The control and experimental groups were compared with the independent or paired two-sample $t$ test, as appropriate. Frequency data were evaluated by the Fisher's exact probability test.

\section{Results}

\section{Lectin histochemical detection of NEU activity}

To determine whether NEU treatment in vitro is sufficient to bring about tissue-specific effects, we evaluated the presence of sialylated glycoproteins by lectin histochemistry. Distribution patterns of sialylated glycoproteins in the hippocampal formation of 1- to 3-week-old rats were examined with the SNA-I lectin, which specifically binds to terminal Neu5Ac $\alpha(2,6) \mathrm{Gal} / \mathrm{Gal}-$ NAc motifs (Shibuya et al., 1987). NEU from two different sources was used for these experiments: one with and another without trace protease activity. Probing untreated brain sections with SNA-I produced an intense vascular staining together with a weak parenchymal staining (Fig. 1A). As expected, sections treated with NEU alone showed a greatly reduced overall staining with SNA-I (Fig. $1 B$ ), which indicates that the number of Neu5Ac $\alpha(2,6) \mathrm{Gal} / \mathrm{GalNAc}$ groups was markedly decreased by NEU treatment. NEU treatment should not completely abolish SNA-I staining, because sialic acid removal creates terminal galactose residues that are weakly bound by the lectin. The intensity of staining of sections treated with NEU blocker before NEU treatment (Fig. 1C) was intermediate, between that of the untreated sections and NEU-alone-treated sections. This result suggests that pretreatment with NEU blocker partially inhibits NEU activity. No differences were found between the effects of NEU with or without trace protease activity on the SNA-I staining pattern. Based on these results, we conclude that the concentration of NEU used in this study was sufficient to bring about tissue-specific effects. Moreover, pretreatment with NEU blocker prevents NEU from completely removing all sialic acid residues in tissue sections.

\section{Effect of NEU treatment on the voltage-gated sodium currents}

Voltage-gated sodium currents $\left(I_{\mathrm{Na}}\right)$ were recorded from hippocampal CA3 pyramidal cells of $\mathrm{P} 10-\mathrm{P} 17$ rats. In the outside- 

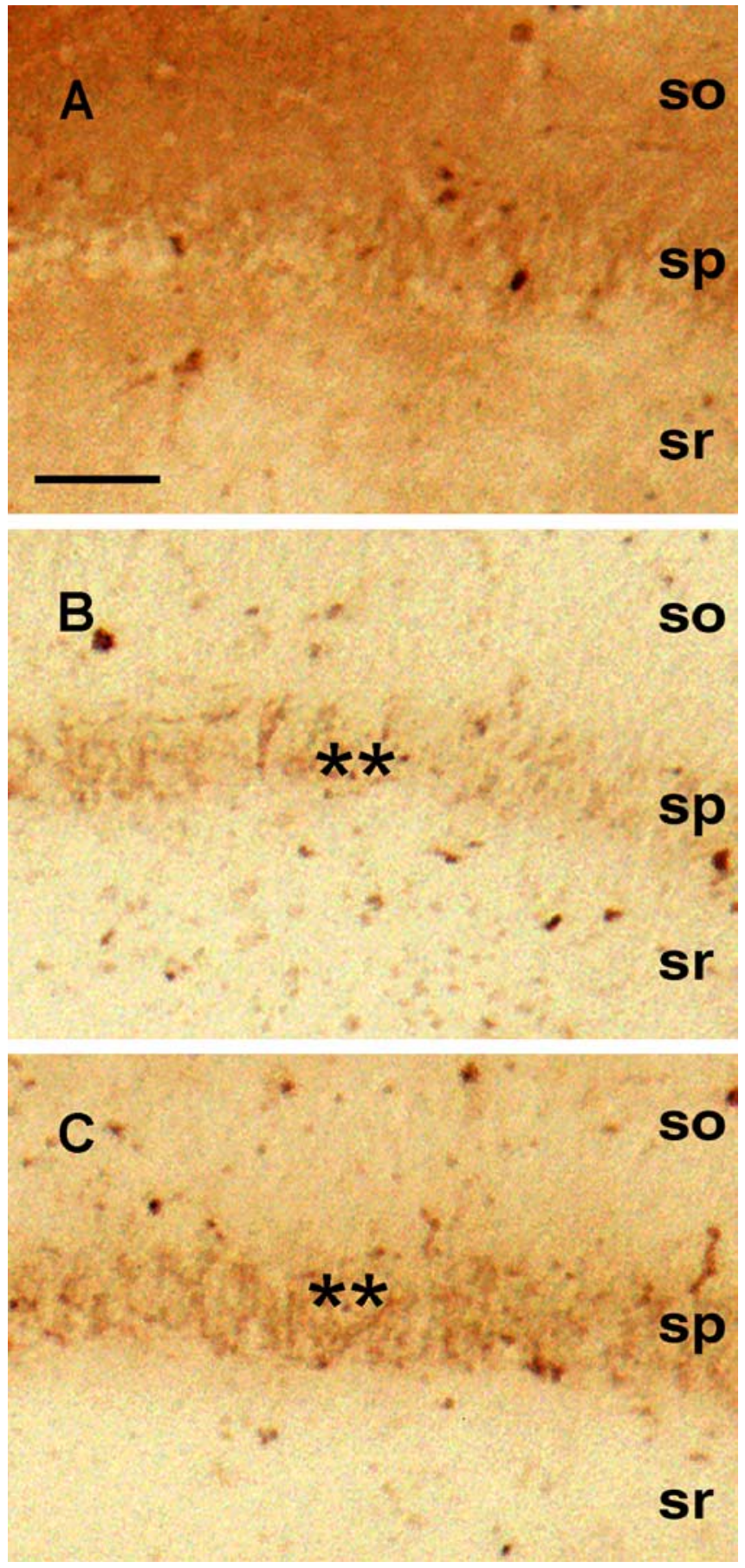

Figure 1. Tissue-specific effects of NEU treatment in the hippocampal formation of rat brain. $A$, Probing control sections with SNA-I showed an intense vascular staining together with a weak parenchymal staining. $\boldsymbol{B}, \boldsymbol{C}$, In sections treated with NEU alone $(\boldsymbol{B})$, the overall SNA-I staining in the pyramidal layer (double asterisks) was greatly reduced compared with sections treated with NEU blocker before NEU treatment (C). Comparable staining patterns were obtained in six independent experiments. Scale bar, $50 \mu \mathrm{m}$. so, Stratum oriens; sp, pyramidal layer; sr, stratum radiatum.

out nucleated patch-clamp recordings, $I_{\mathrm{Na}}$ was evoked by step depolarization $(100 \mathrm{~ms}$ ) from the holding potential of $-80 \mathrm{mV}$ to potentials from -70 to $70 \mathrm{mV}$. These currents activated around $-55 \mathrm{mV}$ and reached peak values around $-25 \mathrm{mV}$. The capacitance of the patched membrane was $2-4 \mathrm{pF}$, and the amplitude of $I_{\mathrm{Na}}$ varied from 30 to $120 \mathrm{pA}$. NEU treatment shifted the average peak of the $I_{\mathrm{Na}}$ current-voltage relationship toward positive po-
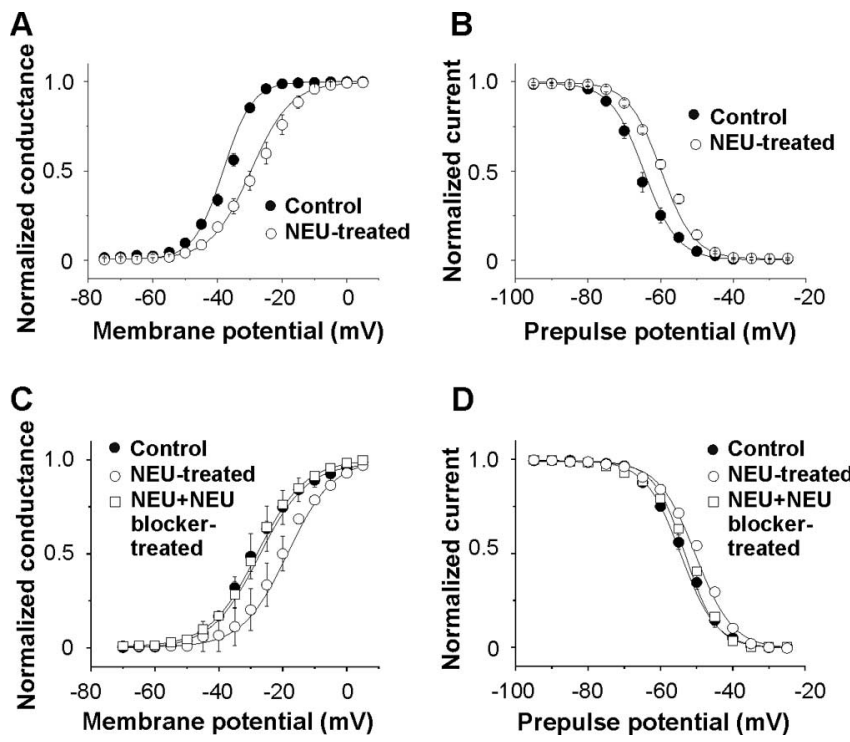

Figure 2. Effect of desialylation of the cellular membrane on the steady-state activation and inactivation of neuronal voltage-gated sodium channels. Nucleated patch $(\boldsymbol{A}, \boldsymbol{B})$ and whole-cell $(C, D)$ recordings were made from CA3 pyramidal neurons correspondingly from P10 - P17 and P2-P5 rats. Summarized voltage dependences of the normalized conductance $(A, C)$ and steady-state inactivation $(\boldsymbol{B}, \boldsymbol{D})$ of sodium channels recorded from $(A 3$ pyramidal neurons from control (filled circles), NEU-treated (open circles), and NEU/NEU blocker-treated (open squares) hippocampal slices fitted by a Boltzmann function are shown. Values are mean \pm SEM.

tentials. The voltage of half-maximal conductance of sodium channel was significantly shifted from $-38.2 \pm 0.3$ for control slices to $-29.6 \pm 0.5$ for NEU-treated slices $(p<0.001)$ (Fig. $2 A)$. The steady-state inactivation curve obtained from the slices treated with NEU also shifted to depolarizing values by $\sim 5 \mathrm{mV}$ $(p=0.004)$ (Fig. 2B, Table 1$)$.

It has been well documented that change in the extracellular divalent cation concentration shifts current-voltage relationships for voltage-gated channels possibly via an effect on membrane surface charges (Frankenhaeuser and Hodgkin, 1957; Hille, 1968; Hille et al., 1975; Green and Andersen, 1991; Bennett et al., 1997). Decreasing $\left[\mathrm{Ca}^{2+}\right]_{\mathrm{o}}$ from 2 to $1 \mathrm{~mm}$ resulted in a significant negative shift of the steady-state activation $(p<$ 0.001 ) of sodium currents (Table 1 ). Because $\mathrm{Ca}^{2+}$ nonspecifically shields the negative charges on the membrane surface, we anticipated that NEU-treated slices would exhibit a less pronounced $\left[\mathrm{Ca}^{2+}\right]_{\mathrm{o}}$-dependent effect on the activation properties of $\mathrm{Na}^{+}$channels. Indeed, the shift of steady-state activation obtained from NEU-treated neurons produced by $1 \mathrm{mM}\left[\mathrm{Ca}^{2+}\right]_{\mathrm{o}}$ was not significant $(p=0.56)$ (Table 1$)$. Decreasing $\left[\mathrm{Ca}^{2+}\right]_{\mathrm{o}} \mathrm{did}$ not produce a significant shift in steady-state half-inactivation voltage of sodium current in control $(p=0.09)$ and NEU-treated $(p=0.31)$ cells.

Nucleated patched membrane could contain different numbers of sodium channels because of their heterogeneous distribution on the cellular membrane. To examine the effect of desialylation on the amplitude of sodium current, we performed patchclamp recordings in whole-cell configuration from CA3 pyramidal cells of P2-P5 rats. The amplitude of $I_{\mathrm{Na}}$ from NEUtreated cells $(615.8 \pm 150.3 \mathrm{pA} n=23)$ was not significantly different from the amplitude of $I_{\mathrm{Na}}$ from control cells $(665.4 \pm$ $160.0 \mathrm{pA} ; n=25)$. The voltage of half-maximal conductance was significantly shifted from $-27.5 \pm 0.6 \mathrm{mV}$ for control slices to $-18.4 \pm 0.5 \mathrm{mV}$ for NEU-treated slices $(p<0.001)$ in P2-P5 rats (Fig. $2 C$ ). The steady-state inactivation curve obtained from the 
Table 1. Effect of the extracellular $\mathrm{Ca}^{2+}$ on the kinetic properties of voltage-gated sodium channels with different levels of sialylation

\begin{tabular}{|c|c|c|c|c|c|c|}
\hline \multirow[b]{2}{*}{ Groups } & \multirow[b]{2}{*}[\mathrm{Ca}^{2+}]{$_{0}(\mathrm{~mm})$} & \multirow[b]{2}{*}{ Number of cells } & \multicolumn{2}{|c|}{ Steady-state activation } & \multicolumn{2}{|c|}{ Steady-state inactivation } \\
\hline & & & $V_{1 / 2}(\mathrm{mV})$ & Slope (mV) & $V_{1 / 2}(\mathrm{mV})$ & Slope (mV) \\
\hline \multirow[t]{2}{*}{ Control } & 2 & 12 & $-38.2 \pm 0.3$ & $4.4 \pm 0.1$ & $-64.5 \pm 0.4$ & $4.6 \pm 0.2$ \\
\hline & 1 & 11 & $-45.3 \pm 0.2^{*}$ & $4.6 \pm 0.1$ & $-68.0 \pm 0.4$ & $4.3 \pm 0.2$ \\
\hline \multirow[t]{2}{*}{ NEU } & 2 & 10 & $-29.6 \pm 0.5$ & $6.1 \pm 0.2$ & $-59.8 \pm 0.2$ & $4.5 \pm 0.1$ \\
\hline & 1 & 8 & $-32.2 \pm 0.5$ & $5.1 \pm 0.2$ & $-62.0 \pm 0.4$ & $4.2 \pm 0.1$ \\
\hline
\end{tabular}

Values are the mean \pm SEM. For each group of cells exposed to 2 or $1 \mathrm{~mm}\left[\mathrm{Ca}^{2+}\right]_{0}$, the values were compared with test significance as follows: ${ }^{*} p<0.01$.

$10 \mathrm{mM}\left[\mathrm{K}^{+}\right] / \mathrm{low}\left[\mathrm{Mg}^{2+}\right]$

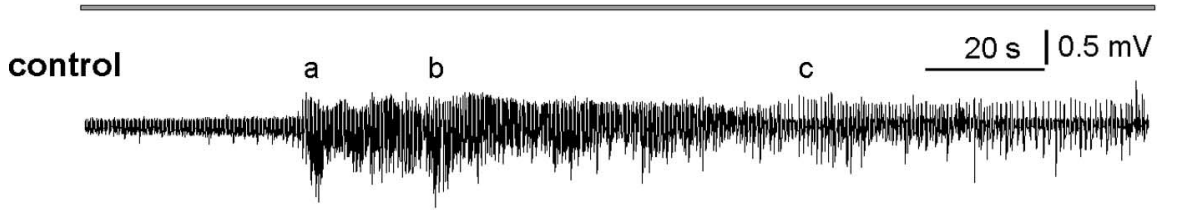

initial bursting discharge

a

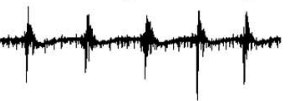

NEU-treated
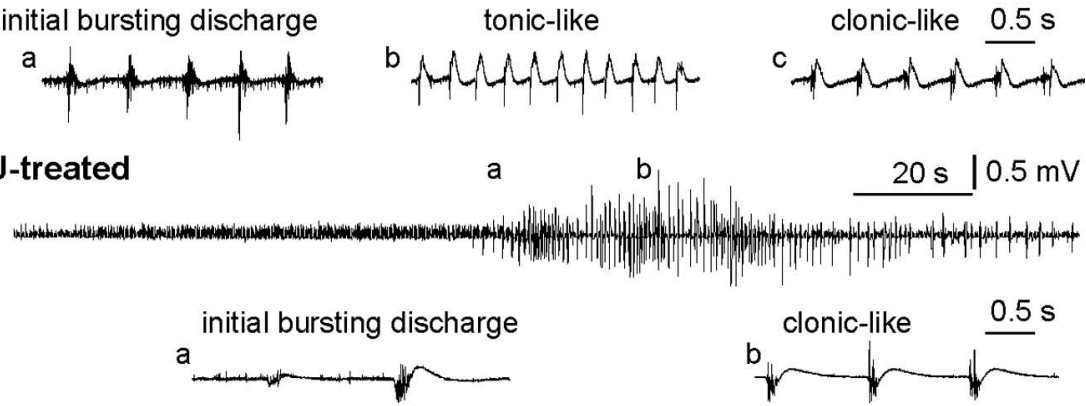

a
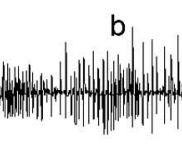

w
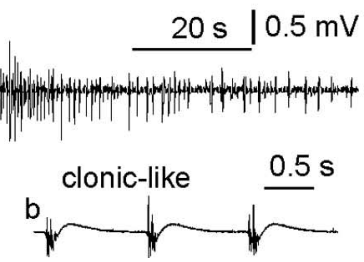

Figure 3. Effect of NEU treatment on epileptiform activity in vitro. An extracellular field potential was recorded from the $C A 3$ pyramidal cell layer of brain slices from P8 - P21 rats. Tonic-like and clonic-like epileptiform activity was induced by $10 \mathrm{~mm}$ $\left[\mathrm{K}^{+}\right]_{0} /$ low $\left[\mathrm{Mg}^{2+}\right]_{0}$ ACSF, and recordings were simultaneously obtained from control (top) and NEU-treated (bottom) slices. Examples of initial bursting and tonic-like and clonic-like discharges are shown on an expanded time scale.

cells treated with NEU also shifted to depolarizing values by $\sim 5$ $\mathrm{mV}(p<0.001)$ (Fig. 2D).

To determine whether any changes in kinetic properties of sodium channels after treatment of slices with NEU was secondary to effects other than NEU activity, we exposed slices to a NEU blocker before NEU (see Materials and Methods). The addition of NEU blocker abrogated NEU effects (Fig. 2C,D). In addition, we did not find any differences in the kinetic properties of sodium channels from cells treated by NEU blocker alone and nontreated control slices (data not shown).

\section{Effect of NEU treatment on the RMP and AP threshold}

In the next set of experiments, resting membrane potential (RMP) and AP threshold were examined in NEU-treated and untreated CA3 pyramidal cells in current-clamp mode from P8P21 rats. There were not significant differences in the RMP recorded from control and NEU-treated cells $[-67.6 \pm 1.2 \mathrm{mV}$ $(n=14)$ vs $-67.9 \pm 2.2 \mathrm{mV}(n=18)$, respectively; $p=0.90]$. In control conditions, AP threshold was $-41.9 \pm 0.6 \mathrm{mV}(n=14)$. In NEU-treated cells, AP threshold was $-37.8 \pm 0.7 \mathrm{mV}(n=18)$ (i.e., $4 \mathrm{mV}$ more depolarized than in control slices) $(p<0.001)$. It was shown previously that increasing the $\left[\mathrm{Ca}^{2+}\right]_{\mathrm{o}}$ increases the firing threshold (Fricker et al., 1999). In 12 control and 14 NEUtreated cells, external calcium was raised to $5 \mathrm{~mm}$. In both conditions, we observed an increase in the threshold of AP initiation. These changes were significantly less pronounced in the NEUtreated cells than in nontreated cells (by $-10.5 \pm 1.3 \mathrm{mV}$ in NEU-treated cells vs $-14.5 \pm 1.0 \mathrm{mV}$ in control cells; $p=0.02$ ).
Effect of NEU treatment on the highpotassium-induced seizures in vitro We hypothesized that the depolarizing shift in the activation of sodium channels and AP threshold produced by desialylation would reduce network excitability. To test this hypothesis, we used a highpotassium/low-magnesium $(10 \mathrm{~mm}$ $\left[\mathrm{K}^{+}\right]_{\mathrm{o}} /$ low $\left[\mathrm{Mg}^{2+}\right]_{\mathrm{o}}$ ) model of ictogenesis in a hippocampal slice preparation (Isaev et al., 2005). We performed extracellular field potential recordings from the CA3 pyramidal cell layer of the hippocampus in P8-P21 rats. Recordings were made simultaneously from the pairs of control and NEU-treated slices $(n=32$ pairs of slices) (Fig. 3). A comparative analysis showed that after $2 \mathrm{~h}$ of incubation with $\mathrm{NEU}$, the frequency of multiple unit activity (MUA) recorded from the NEUtreated slices was significantly lower than the frequency of MUA recorded from control slices $(26.3 \pm 3.6$ vs $15.3 \pm 2.9 \mathrm{~Hz} ; p=$ $0.03)$, consistent with the positive shift in sodium channel activation and AP threshold described above. Bath application of $10 \mathrm{~mm}\left[\mathrm{~K}^{+}\right]_{\mathrm{o}} /$ low $\left[\mathrm{Mg}^{2+}\right]_{\mathrm{o}}$ ACSF induced increases in MUA firing in both control and NEU-treated slices that developed into initial bursting discharges and then into recurrent tonic-like activity in 87 and $38 \%$ and clonic-like activity in 100 and $77 \%$ of control and NEUtreated slices, respectively. The onset of epileptiform activity was significantly delayed (120.9 \pm 11.5 vs $196.6 \pm 14.0 s ; p<0.001)$, and the maximal population spike (PS) frequency was significantly reduced (3.7 \pm 0.4 vs $2.5 \pm 0.3 \mathrm{~Hz} ; p=0.02)$ in NEUtreated slices comparatively to control slices.

Effect of exogenous NEU and NEU antagonist on the highpotassium-induced seizures in vivo

In the next set of experiments, we tested the effect of NEU on seizure threshold in vivo using the high-potassium/lowmagnesium model in P8-P21 rats previously described in our laboratory (Isaev et al., 2005). After $2 \mathrm{~h}$ of injection of NEU, epileptiform activity was induced by repetitive injection of the 10 $\mathrm{mm}\left[\mathrm{K}^{+}\right]_{\mathrm{o}} /$ low $\left[\mathrm{Mg}^{2+}\right]_{\mathrm{o}}$ ACSF into the hippocampal CA3 pyramidal layer of nonanesthetized rat (Fig. $4 A$ ). In the control group, $10 \mathrm{~mm}\left[\mathrm{~K}^{+}\right]_{\mathrm{o}} /$ low $\left[\mathrm{Mg}^{2+}\right]_{\mathrm{o}}$ inevitably induced ictal-like discharges in all animals tested $(n=10)$, whereas seizures were absent in six of eight $(75 \%)$ rats treated with NEU $(p=0.05)$ (Fig. 4B). The maximal PS frequency during the seizure in NEUtreated rats was significantly lower than the PS frequency in control rats $(p=0.02)$ (Fig. $4 D)$. In addition, seizures in NEUtreated rats were significantly shorter than in the control group $(p<0.005)$ (Fig. 4C). These results suggest that NEU treatment 
efficiently increases seizure threshold in vivo, in agreement with our results obtained in slices in vitro.

Because NEU effectively reduced seizure susceptibility, we next asked whether endogenous NEU participates in the regulation of this phenomenon. We studied the effects of a NEU blocker on hippocampal seizures using the above-described in vivo protocol. The NEU blocker was delivered to the CA3 region of the rat hippocampus in vivo. After $2 \mathrm{~h}$ of injection of the NEU blocker $(5 \mathrm{~mm}, 30 \mu \mathrm{l})$, $10 \mathrm{~mm}\left[\mathrm{~K}^{+}\right]_{\mathrm{o}} /$ low $\left[\mathrm{Mg}^{2+}\right]_{\mathrm{o}}$ ACSF was applied to the same region of the hippocampus (Fig. 4A). All 10 rats had ictal-like activity in response to $10 \mathrm{~mm}\left[\mathrm{~K}^{+}\right]_{\mathrm{o}} / \mathrm{low}\left[\mathrm{Mg}^{2+}\right]_{\mathrm{o}}$ ACSF injection. In contrast with a control group of rats in which seizures were triggered on the fourth to eighth injection, seizures appeared on the first to third injection in the rats treated with the NEU blocker (control, $5.7 \pm$ 0.5 vs NEU blocker, $2.0 \pm 0.3 ; p<0.001$ ) (Fig. $4 B$ ). Also, seizures were significantly longer in rats treated by the NEU blocker than in rats from the control group $(p<$ 0.005) (Fig. 4C). We did not find a significant difference in maximal PS frequency between the controls and the NEU blocker-treated groups $(p=0.94)$ (Fig. $4 D)$.

\section{Effect of NEU treatment in kindling model of epilepsy}

The goal of the next set of experiments was to determine whether NEU reduces seizure intensity in a kindling model of epilepsy. The effect of NEU with and without blocker was tested in animals that were fully kindled. Like the in vivo studies described above, we used higher concentrations of NEU and NEU blocker for these experiments than for the in vitro studies. We also studied the effect of the NEU blocker with and without NEU on kindling stage and $\mathrm{AD}$ duration.

After full kindling, rats $(n=10)$ were administered NEU with trace protease and NEU without trace protease. No differences were found between the two forms of NEU, and the results are combined here. Before administration of NEU, all of the rats had three consecutive stage 5 seizures. One hour after the NEU, there was no difference in seizure stage or $\mathrm{AD}$ duration. However, when the animals were stimulated $12 \mathrm{~h}$ after the NEU administration, there was a dramatic and highly significant drop in both kindling stage $(t=8.450 ; p<0.0001)$ and $\mathrm{AD}$ duration $(t=$ 5.799; $p<0.0001$ ) (Fig. 5). No behavioral abnormalities were seen in the rats receiving NEU. The rats had normal activity level, normal posture, and responded normally to handling.

We then tested whether administration of NEU blocker resulted in any change in the kindling stage or the AD duration in seven rats. The NEU blocker had no effect on kindling stage (before blocker, $5.0 \pm 0.0$; after blocker, $4.4 \pm 0.4 ; p=0.11$ ) or $\mathrm{AD}$ duration (before blocker, $58.7 \pm 5.5 \mathrm{~s}$; after blocker, $58.2 \pm$ $4.7 \mathrm{~s} ; p=0.94)$. We then administered NEU after the NEU blocker. As shown in Figure 5, the NEU administrated after NEU
B

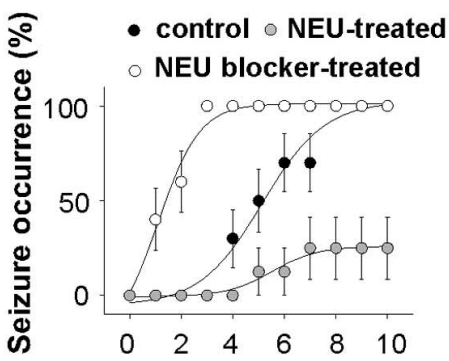

Number of injections

C

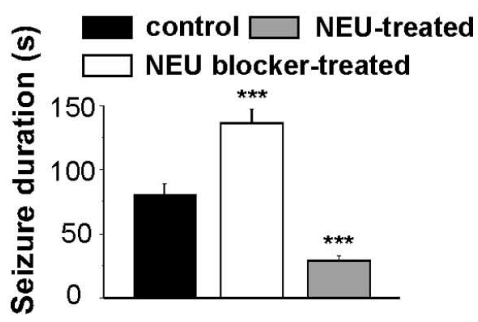

D

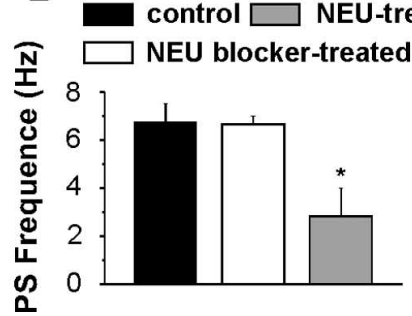

Figure 4. Comparison of effects of NEU treatment versus NEU blocker treatment on high-potassium-induced seizures in vivo. Hippocampal seizures were induced by $10 \mathrm{~mm}\left[\mathrm{~K}^{+}\right]_{0} / \mathrm{low}\left[\mathrm{Mg}^{2+}\right]_{0}$ ACSF in P8-P21 rats in vivo. Extracellular field potentials were recorded from the CA3 pyramidal cell layer. $\boldsymbol{A}$, Responses to repetitive microinjections (arrows) of $10 \mathrm{mM}$ $\left[\mathrm{K}_{0}\right]_{0} \mathrm{WW}\left[\mathrm{Mg}^{2+}\right]_{0} \mathrm{ACSF}$ (shown at the same voltage scale for all traces). Note that epileptiform events are induced from the events (asterisks) are shown below on an expanded time scale to reveal phases: (1) tonic- and (2) clonic-like activity. $\boldsymbol{B}$, Summary plot of seizure probability as a function of the number of injections. $C, D$, Duration of ictal-like activity $(\boldsymbol{C})$ and maximal PS frequency $(\boldsymbol{D})$ for control (black bar; $n=10$ ), NEU-treated (gray bar; $n=8$ ), and NEU blocker-treated (white bar; $n=10$ ) rats at P8-P21. Statistical comparisons were performed using the $t$ test, ${ }^{*} p<0.05$; ${ }^{* * *} p<0.005$.

A

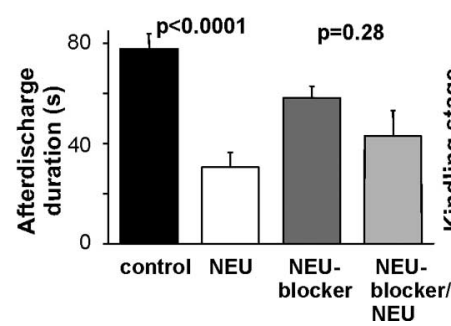

B

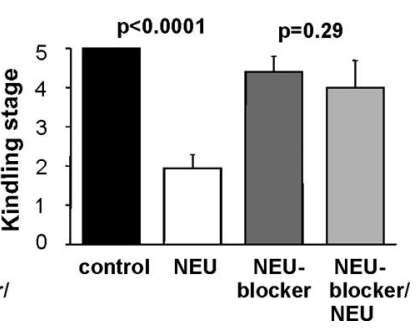

Figure 5. Effect of NEU treatment in kindling model of epilepsy. Comparison of effect of NEU on $\mathrm{AD}(\boldsymbol{A})$ and kindling stage $(\boldsymbol{B})$ in fully kindled rats before (black bars) and after (white bars) NEU was injected in rats not treated with the NEU blocker and before (dark gray bars) and after (light gray bars) NEU was administrated in rats that received NEU blocker injection. NEU significantly reduced $A D$ duration and kindling stage in control rats, whereas the NEU administered after the NEU blocker had no significant effect on kindling stage or AD.

blocker had no significant effect on either kindling stage $(t=$ $1.45 ; p=0.29)$ or $\mathrm{AD}$ duration $(t=1.39 ; p=0.28)$.

Neither the blocker nor NEU had any adverse effect on behavior. Other than for some gliosis around the catheter tip, no cell 
loss was seen in any of the animals that received NEU or the blocker.

\section{Discussion}

Sialic acids play an important role in many neuronal processes including axonal growth and synaptic activity-induced and neuronal-glial plasticity (Bonfanti, 2006) Charged sialic acid residues have also been proposed to be the moieties responsible for the effects of divalent ions on channel gating behavior (RecioPinto et al., 1990; Bennett et al., 1997; Castillo et al., 1997; Zhang et al., 1999; Johnson et al., 2004). Here we show that sialylation of the external surface of plasma membrane modulates sodium currents and AP threshold in CA3 pyramidal cells and excitability of the hippocampal network.

The activation and inactivation properties of voltage-gated sodium channels from CA3 pyramidal cells were greatly affected after $2 \mathrm{~h}$ of incubation of hippocampal slices with NEU. Bennett et al. (1997) showed that enzymatic removal of sialic acid residues from Chinese hamster ovary cells transfected with rat skeletal muscle sodium channels (rSkM1) and expression of rSkM1 in a sialylation-deficient cell line resulted in a depolarizing shift of $\sim 10 \mathrm{mV}$ in sodium channel gating in muscle. In the same study, it was shown that recombinant deletion of likely glycosylation sites from the rSkM1 sequence resulted in mutant channels that gated at voltages up to $10 \mathrm{mV}$ more positive than wild-type channels. We found that NEU treatment altered voltage dependence of activation of neurons in the same manner. A shift in the steadystate inactivation of sodium channels was less prominent than the shift in voltage-dependant activation, which suggests that the sialic acid residues have a very local and selective influence on voltage-sensitive mechanisms of the channel.

Divalent ions are known for their ability to shield membrane surface charge (Frankenhaeuser and Hodgkin, 1957; Campbell and Hille, 1976). In our experiments, the effect of external calcium on steady-state activation of sodium channels was diminished in NEU-treated cells. A shift in steady-state halfinactivation voltage of sodium current produced by decreasing $\left[\mathrm{Ca}^{2+}\right]_{\mathrm{o}}$ was also diminished under conditions of reduced sialylation, but to a lesser extent. These findings also support the idea that sialic acid residues contribute to a significant part of surface charge near the voltage-sensitive site of the sodium channel.

The depolarizing shift in the gating kinetics of the sodium channels leads to an increasing AP threshold in the NEU-treated neurons and, as a result, to decreasing MUA. In our experiments, the frequency of MUA in NEU-treated slices was lower than in control slices. We suggest that the reduction in spontaneous activity in the NEU-treated slices is a result of increasing AP threshold that prevents excitation from weak synaptic connections. The increasing threshold for APs has less affect on stronger excitatory synaptic connections than weaker ones, which cannot overcome the additional potential barrier to postsynaptic cell excitation. For inhibitory connections, there is no such barrier to overcome, and we speculate that desialylation affects excitatory connectivity between cells with weak synaptic connection and thus may affect synchronized activity (Izhikevich, 1999).

In view of our findings, a recent study demonstrated that dorsal root ganglion neurons became hyperexcitable after a chronic constriction injury, as indicated by a more depolarized RMP and a lowered threshold of current (Peng et al., 2004). The excitability of injured dorsal root ganglion cells in this study was reduced when the extracellular sialic acid was removed by pretreatment with NEU.

In the present work, the effect of reduced levels of sialic acid residues on network excitability was studied in vitro and in vivo with the high-potassium model of epilepsy. As predicted from the patch-clamp studies, desialylation of the cellular surface produced a marked reduction in seizure susceptibility in both in vitro and in vivo models.

The antiseizure effects of NEU in the high-potassium model of epilepsy led us to determine whether NEU would be effective in preventing seizures in the kindling model, a widely used in vivo model to assess both the antiepileptogenic and anticonvulsive properties of compounds. After full kindling, animals consistently have partial seizures and secondary generalization with subsequent stimulations (McNamara et al., 1985). We found that NEU administered focally to the CA1 region had a marked anticonvulsant effect with marked reductions in both the kindling stage and $\mathrm{AD}$ duration; indeed, the majority of rats had no seizures after NEU treatment. Effects were not altered when the kindling stimulation was given $1 \mathrm{~h}$ after the NEU. However, a reduction in seizure severity was observed when the animals were tested $12 \mathrm{~h}$ later. These findings suggest that the effect of NEU was attributable to enzymatic degradation of sialic acid rather than a direct anticonvulsant effect of NEU. Seizures were not altered when the NEU blocker was administered concurrently with the NEU, suggesting that the suppressant effects of NEU were specific to the desialylation activity of NEU. Despite the suppressant effect of NEU on seizures, the animals had no behavioral impairment.

It has been well documented that patients with disorders of free sialic acid storage (infantile sialic acid storage diseases and Salla disease) have developmental delay with marked cognitive and motor impairment and frequently have severe seizures (Erikson et al., 2002; Wreden et al., 2005). Although these clinical observations demonstrate the importance of sialic acids in brain excitability, the underlying mechanisms remain unknown. Our findings that injection of NEU blocker alone into the hippocampal CA3 pyramidal layer aggravated seizures suggest that endogenous NEU participates in the regulation of neuronal activity. We propose that an increase in sialic acid-negative surface charge resulting in reduced AP threshold and increased excitability could be one of the important factors of the pathogenesis of epilepsy associated with these inherited disorders.

In conclusion, several lines of evidence suggest that regulation of the level of sialylation is a powerful mechanism to control the surface charge as well as neuronal and network excitability: (1) NEU treatment produced a significant positive shift in the steadystate activation and inactivation voltages of sodium channels and AP threshold; (2) NEU treatment masked the effect of extracellular calcium on kinetic properties of sodium channels and AP threshold; (3) NEU treatment resulted in a marked increase in the seizure threshold; and (4) NEU blockade resulted in a reduction in seizure threshold. Although preliminary, our findings show that reducing surface charge could be of considerable value in treating epilepsy. The pronounced suppression of seizures coupled with the apparent low toxicity suggests that this may be a useful therapeutic approach for treating epilepsy. Whereas developing a delivery system that will target specific brain areas for desialylation will be a challenge, modifying cerebral excitability through alteration of surface charge appears to be quite promising.

\section{References}

Bennett E, Urcan MS, Tinkle SS, Koszowski AG, Levinson SR (1997) Contribution of sialic acid to the voltage dependence of sodium channel gating. A possible electrostatic mechanism. J Gen Physiol 109:327-343. 
Bennett ES (2002) Isoform-specific effects of sialic acid on voltagedependent $\mathrm{Na}+$ channel gating: functional sialic acids are localized to the S5-S6 loop of domain I. J Physiol (Lond) 538:675-690.

Bonfanti L (2006) PSA-NCAM in mammalian structural plasticity and neurogenesis. Prog Neurobiol 80:129-164.

Campbell DT, Hille B (1976) Kinetic and pharmacological properties of the sodium channel of frog skeletal muscle. J Gen Physiol 67:309-323.

Castillo C, Díaz ME, Balbi D, Thornhill WB, Recio-Pinto E (1997) Changes in sodium channel function during postnatal brain development reflect increases in the level of channel sialylation. Dev Brain Res 104:119-130.

Erikson A, Aula N, Aula P, Mansson JE (2002) Free sialic acid storage (Salla) disease in Sweden. Acta Paediatr 91:1324-1327.

Erisir A, Lau D, Rudy B, Leonard CS (1999) Function of specific K(+) channels in sustained high-frequency firing of fast-spiking neocortical interneurons. J Neurophysiol 82:2476-2489.

Frankenhaeuser B, Hodgkin AL (1957) The action of calcium on the electrical properties of squid axons. J Physiol (Lond) 11:218-244.

Fricker D, Verheugen JA, Miles R (1999) Cell-attached measurements of the firing threshold of rat hippocampal neurones. J Physiol (Lond) 517:791-804.

Green WN, Andersen OS (1991) Surface charges and ion channel function. Annu Rev Physiol 53:341-359.

Hanck DA, Sheets MF (1992) Extracellular divalent and trivalent cation effects on sodium current kinetics in single canine cardiac Purkinje cells. J Physiol (Lond) 454:267-298.

Hille B (1968) Charges and potentials at the nerve surface. Divalent ions and pH. J Gen Physiol 51:221-236.

Hille B, Woodhull AM, Shapiro BI (1975) Negative surface charge near sodium channels of nerve: divalent ions, monovalent ions, and $\mathrm{pH}$. Philos Trans R Soc Lond B Biol Sci 270:301-318.

Isaev D, Isaeva E, Khazipov R, Holmes GL (2005) Anticonvulsant action of GABA in the high potassium-low magnesium model of ictogenesis in the neonatal rat hippocampus in vivo and in vitro. J Neurophysiol 94:2987-2992.

Izhikevich E (1999) Weakly pulse-coupled oscillators, FM interactions, synchronization, and oscillatory associative memory. IEEE Trans Neuron Netw 10:508-526.

Johnson D, Bennett ES (2006) Isoform-specific effects of the beta2 subunit on voltage-gated sodium channel gating. J Biol Chem 281:25875-25881.

Johnson D, Montpetit ML, Stocker PJ, Bennett ES (2004) The sialic acid component of the $\beta_{1}$ subunit modulates voltage-gated sodium channel function. J Biol Chem 279:44303-44310.

Khazipov R, Khalilov I, Tyzio R, Morozova E, Ben-Ari Y, Holmes GL (2004) Developmental changes in GABAergic actions and seizure susceptibility in the rat hippocampus. Eur J Neurosci 19:590-600.

Kostyuk PG, Krishtal OA (1977) Effects of calcium and calcium-chelating agents on the inward and outward current in the membrane of mollusc neurones. J Physiol (Lond) 270:569-580.

Leinekugel X, Khazipov R, Cannon R, Hirase H, Ben-Ari Y, Buzsaki G (2002) Correlated bursts of activity in the neonatal hippocampus in vivo. Science 296:2049-2052.
Lowry OH, Rosebrough NJ, Farr AL, Randall RJ (1951) Protein measurement with the Folin phenol reagent. J Biol Chem 193:265-275.

McNamara JO, Bonhaus DW, Shin C, Crain BJ, Gellman RL, Giacchino JL (1985) The kindling model of epilepsy: a critical review. CRC Crit Rev Clin Neurobiol 1:341-391.

Messner DJ, Feller DJ, Scheuer T, Catterall WA (1985) The sodium channel from rat brain: separation and characterization of subunits. J Biol Chem 260:10597-10604.

Miller JA, Agnew WS, Levinson SR (1983) Principle glycopeptide of the tetrodotoxin/saxitoxin binding protein from Elelctrophorus electricus. Isolation and partial chemical and physical characterization. Biochemistry 22:462-470.

Misonou H, Trimmer JS (2004) Determinants of voltage-gated potassium channel surface expression and localization in mammalian neurons. Crit Rev Biochem Mol Biol 39:125-145.

Paxinos G, Watson C (1998) The rat brain in stereotaxic coordinates, Ed 4. San Diego: Academic.

Peng XQ, Zhang XL, Fang Y, Xie WR, Xie YK (2004) Sialic acid contributes to hyperexcitability of dorsal root ganglion neurons in rats with peripheral nerve injury. Brain Res 102:185-193.

Racine RJ (1972) Modification of seizure activity by electrical stimulation: II. Motor seizures. Electroencephalogr Clin Neurophysiol 32:281-294.

Recio-Pinto E, Thornhill WB, Duch DS, Levinson SR, Urban BW (1990) Neuraminidase treatment modifies the function of electroplax sodium channels in planar lipid bilayers. Neuron 5:675-684.

Roberts RH, Barchi RL (1987) The voltage-sensitive sodium channel from rabbit skeletal muscle. Chemical characterization of subunits. J Biol Chem 262:2298-2303.

Sather W, Dieudonne S, MacDonald JF, Ascher P (1992) Activation and desensitization of N-methyl-D-aspartate receptors in nucleated outsideout patches from mouse neurones. J Physiol (Lond) 450:643-672.

Sato Y, Endo T (1999) Differential expression of sialoglycoproteins in the rat hippocampus and its changes during aging. Neurosci Lett 262:49-52.

Shibuya N, Goldstein IJ, Broekaert WF, Nsimba-Lubaki M, Peeters B, Peumans WJ (1987) The elderberry (Sambucus nigra L.) bark lectin recognizes the Neu5Ac(alpha 2-6)Gal/GalNAc sequence. J Biol Chem 262:1596-1601.

Stocker PJ, Bennett ES (2006) Differential sialylation modulates voltagegated $\mathrm{Na}+$ channel gating throughout the developing myocardium. J Gen Physiol 127:253-265.

Tyrrell L, Renganathan M, Dib-Hajj SD, Waxman SG (2001) Glycosylation alters steady-state inactivation of sodium channel Nav1.9/NaN in dorsal root ganglion neurons and is developmentally regulated. J Neurosci 21:9629-9637.

Wieraszko A (1985) Attenuation of inhibitory processes in the central nervous system by tetanus toxin: an in vitro study on rat hippocampal slices. Life Sci 37:2059-2065.

Wreden CC, Wlizla M, Reimer RJ (2005) Varied mechanisms underlie the free sialic acid storage disorders. J Biol Chem 280:1408-1416.

Zhang Y, Hartmann HA, Satin J (1999) Glycosylation influences voltagedependent gating of cardiac and skeletal muscle sodium channels. J Membr Biol 171:195-207. 